\title{
Comunicação
}

[Communication]

\section{Hospedeiros de Triplasta atrocoxalis (Ashmead) (Hymenoptera: Figitidae: Eucoilinae) coletados em fezes de bovinos e búfalos no Brasil}

\author{
[Hosts of Triplasta atrocoxalis (Ashmead) (Hymenoptera: Figitidae: Eucoilinae) colletected in \\ cattle and buffalo dung in Brazil] \\ C.H. Marchiori \\ Centro Federal de Educação Tecnológica de Urutaí - UNED \\ Caixa Postal 92 \\ 75650-000 - Morrinhos, GO
}

Entre os meios de controle das moscas, os mais utilizados são os inseticidas químicos que podem perder sua eficiência à medida que as populações tornam-se resistentes aos mesmos (Silveira et al., 1989).

Estudos indicam que os mais importantes controladores nos criadouros de animais são os predadores, competidores e parasitóides (Geden et al., 1988; Marchiori, 2006; Marchiori, 2007). A viabilidade do uso de controladores e as vantagens de seu emprego na agricultura e na criação de animais são indiscutíveis, em razão de seu baixo custo, facilidade de manuseio, seletividade e não contaminação ambiental (Silveira et al., 1989).

A subfamília Eucoilinae, apesar de cosmopolita, é pouco conhecida. Ela é representada por cerca de 1000 espécies e 70 gêneros espalhados pelo mundo. São endoparasitóides primários coinobiontes de larvas dípteros de ciclorrafos, inclusive fitófagos. Encontra-se em grande número ao redor de estrumes, carcaças em decomposição e locais ricos em dípteros na região neotropical (Gauld e Bolton, 1988; Díaz e Gallardo, 1996).

O objetivo deste estudo foi verificar a porcentagem de parasitismo e os hospedeiros de Triplasta atrocoxalis (Ashmead) (Hymenoptera: Figitidae: Eucoilinae) em fezes de búfalos e bovinos no Brasil.

Recebido em 13 de setembro de 2007

Aceito em 26 de março de 2008

E-mail: chmarchiori@yahoo.com.br
O experimento foi realizado em três propriedades rurais do sul do estado de Goiás. Dez placas de fezes frescas de bovinos e búfalos foram marcadas imediatamente após sua dejeção, com auxílio de estacas de madeira branca $(30 \mathrm{~cm}$ de altura e $5 \mathrm{~cm}$ de espessura), para determinação precisa do tempo entre a dejeção e a coleta, e permaneceram no campo por 15 dias. Sete amostras foram colhidas e levadas ao laboratório para a extração das pupas pelo método da flotação. Juntamente com as fezes, foram retirados $5 \mathrm{~cm}$ do substrato situado abaixo do local de deposição no solo. As pupas foram retiradas com o auxílio de uma peneira, contadas e individualizadas em cápsulas de gelatina (número 00) até a emergência dos dípteros e/ou dos parasitóides. Os dípteros emergidos foram identificados com auxílio de um microscópio estereoscópio e conservados em álcool $70 \%$. Quinzenalmente, os experimentos com as fezes bovinas e com as de búfalos foram realizados de janeiro de 1998 a junho de 2004 e de maio de 2003 a junho de 2004, respectivamente.

A porcentagem total de parasitismo foi calculada pelo número de pupas parasitadas/número total de pupas coletadas x 100. A porcentagem de parasitismo de cada espécie de parasitóide foi calculada pelo número de pupas parasitadas por espécie de parasitóide/número total de pupas daquele hospedeiro x 100 .

Foram coletadas 6618 pupas de Diptera, das quais emergiram 134 parasitóides solitários da 
espécie T. atrocoxalis, evidenciando $2,0 \%$ de porcentagem de parasitismo (Tab. 1). Em fezes bovinas a porcentagem de parasitismo foi de $2,5 \%$ e, em fezes de búfalos, $0,1 \%$. A pequena porcentagem de parasitismo e a diversidade de hospedeiros coletados em fezes de búfalos deve ser, possivelmente, devido à recente introdução dos búfalos na região de Itumbiara, Goiás, dificultando a capacidade de busca do parasitóide e também ao menor número de coletas realizadas.

Tabela 1. Porcentagem de parasitismo e dos hospedeiros do parasitóide T. atrocoxalis provenientes de fezes de bovinos e de búfalos no sul de Goiás de janeiro de 1998 a dezembro de 2005

\begin{tabular}{llccc}
\hline Substrato & \multicolumn{1}{c}{ Díptero } & $\begin{array}{c}\text { Número de } \\
\text { pupas } \\
\text { obtidas }\end{array}$ & $\begin{array}{c}\text { Número de } \\
\text { pupas } \\
\text { parasitadas }\end{array}$ & Porcentagem \\
\hline Fezes bovinas & Archisepsis scabra & 129 & 8 & 6,2 \\
& Palaeosepsis spp. & 1611 & 101 & 6,3 \\
& Sarcophagula occidua & & & 0,2 \\
Total & & 2893 & 5 & 2,7 \\
Fezes de búfalos & Sphaeroceridae sp. & 37 & 1 & 2,5 \\
& & 4670 & 115 & 0,1 \\
\hline
\end{tabular}

As espécies de hospedeiros que apresentaram maior porcentagem de parasitismo em fezes bovinas foram Palaeosepsis spp. (Diptera: Sepsidae) com 6,3\%. Provavelmente, essa porcentagem seja devido às variações na qualidade e na disponibilidade de recursos alimentares ou pelas densidades dos hospedeiros.

Pouco se conhece atualmente sobre os cinipóideos que se comportam como parasitóides primários de dípteros que se desenvolvem em esterco na região neotropical (Díaz e Gallardo, 1996; Díaz et al., 2000). Aumenta-se com este estudo a bioecologia dos parasitóides de Diptera que se desenvolvem em esterco no Brasil.

Palavras-chave: Diptera, parasitóide, moscas, controle biológico

\section{ABSTRACT}

This study verified the percentage of parasitism and hosts species of the parasitoid Triplasta atrocoxalis (Ashmead) (Hymenoptera: Figitidae: Eucoilinae) in cattle and buffalo dung, collected in the South of Goiás state, Brazil; from January 1998 to June 2004. The pupae were obtained by the flotation method. They were individually placed in gelatin capsules until the emergence of adult dipterous or their parasitoids. The percentage of parasitism in cattle and buffalo dung was $2.5 \% \%$ and $0.1 \%$, respectively.

Keywords: Diptera, parasitoid, flies, biological control

\section{REFERÊNCIAS BIBLIOGRÁFICAS}

DÍAZ, N.; GALLARDO, F. Sobre cinipoideos del Brasil, parasitoides de dipteros estercoleros (Hymenoptera: Cynipoidea). Rev. Soc. Entomol. Argent., v.55, p.127-129, 1996.
DÍAZ, N.B.; GALLARDO, F.E.; MARCHIORI, C.H. Cynipoidea parasitoids of dung-flies in Brazil. II (Insecta: Hymenoptera). An. Soc. Entomol. Bras., v.29, p.469-474, 2000. 
GAULD, I.D.; BOLTON, B. (Eds). The Hymonoptera. Oxford: Oxford University, 1988. $331 \mathrm{p}$.

GEDEN, C.J.; STINNER, R.E; AXTELL, R.C. Predation by predators of the house fly in poultry manure: effects of predator density, feeding history, interspecific interference, and field conditions. Environ. Entomol., v.17, p.320-329, 1988.

MARCHIORI, C.H. Microimenópteros de Musca domestica L. (Díptera: Muscidae) coletados em diferentes substratos em Itumbiara,
Goiás. Arq. Bras. Med. Vet. Zootec., v.58, p.447449, 2006.

MARCHIORI, C.H. Eurytoma sp. (Hymenoptera: Euritomidode) como parasitóide de Fannia pusio (Wiedemann) (Diptera: Fanniidae) no Brasil. Arq. Bras. Med. Vet. Zootec., v.59, p.1084-1085, 2007.

SILVEIRA， G.A.R.; MADEIRA， N.G.; AZEREDO-ESPIN, A.M.L. Levantamento de microhimenóptera parasitóides de dípteros de importância médico-veterinária no Brasil. Mem. Inst. Oswaldo Cruz, v.84, p.505-510, 1989. 